\title{
Antifungal, Antiviral, and Antibacterial Activities of Silver Nanoparticles Synthesized Using Fungi: A Review
}

\author{
Teeba Hashim Mohammed 1, Mohsen Hashim Risan 1, Mohammed Kadhom 2(D), Rasha \\ Raheem $^{3}$ (i) , Emad Yousif 4,* (D) \\ College of Biotechnology, Al-Nahrain University, Baghdad, Iraq \\ 2 Department of Renewable Energy, College of Energy and Environmental Sciences, Alkarkh University of Science, \\ Baghdad, Iraq \\ 3 Department of Pathology, Microbiology, and Immunology, University of South Carolina School of Medicine, Columbia, \\ SC, United States of America \\ 4 Department of Chemistry, College of Science, Al-Nahrain University, Baghdad, Iraq \\ * Correspondence: emad_yousif@hotmail.com;
}

Scopus Author ID 26533612800

Received: 15.06.2020; Revised: 2.07.2020; Accepted: 3.07.2020; Published: 7.07.2020

\begin{abstract}
Nanoparticles (NPs) synthesized from fungi have a significant biocatalytic application, where they were utilized in enzyme immobilization to enriched enzymatic activity. Silver (Ag) NPs produced from fungi was found to have a benign activity in a wound and thermal wound, and function as anti-mosquito and antiviruses. AgNPs were synthesized using cotton fabrics, which displayed an inhibition activity to the development of some bacteria. These silver nanoparticles were prepared through fungi and linked with the main combination and DNA sample of fungi.
\end{abstract}

Keywords: silver nanoparticles; fungi; antiviral; antibacterial; green preparation.

(C) 2020 by the authors. This article is an open-access article distributed under the terms and conditions of the Creative Commons Attribution (CC BY) license (https://creativecommons.org/licenses/by/4.0/).

\section{Introduction}

Biologically synthesized AgNPs have gained great attention among researchers recently due to their environmentally friendly properties, low most, and non-toxic byproducts during the synthesis process [1]. However, several complicated natural bases are used in this technique, for example, fungus and bacteria. Fungi have been commonly used in nanoparticle preparation techniques due to the bio-active complex that occurs in the source, for example, polysaccharide, vitamin, and protein. These mixtures help plummeting agents with normal stabilizers to create nanoparticles from $\mathrm{Ag}^{+}[2,3]$. AgNPs were reported to have antimicrobial activity against a wide range of fungi [4]. This raised the attention of applying AgNPs in various applications, though it is needed to comprehend the mechanism of inhibition via these nanoparticles throughout treatment [5]. The reflection under the electron microscope exhibited that the cells of microorganisms were deceased due to the progression of nanoparticles by the infectious cells' wall [6].

The establishment of depths and barriers on the cells augmented its penetrability by the small nanoparticles, which affected the cytoplasm of cells [7]. Nanoparticles were found to be no longer affecting the fungi inhibition due to the inability to release free silver $(\mathrm{Ag}+)$. This occurred because of the release of $\mathrm{Ag}+$ ions throughout the treatment [8]. This observation was recognized by comparing the influence of nanoparticles on fungi incubated with different sizes of $\mathrm{Ag}^{+}$particles [9]. Consequently, the capability of particles to release silver ion $\left(\mathrm{Ag}^{+}\right)$is 
related to the standard oxidation procedure through antimicrobial experiments [10]. This was assumed to be a feature that increases the particles poisonousness and the oxidation procedure. It happens mostly because of the melted oxygen and protons that present in the medium for growth $[11,12]$. Decreasing the size of the nanoparticles lead to a high antimicrobial action, where a high surface area to volume ratio and high affinity intended that the smaller nanoparticles could quickly release free $\mathrm{Ag}^{+}$compared with the bigger size particles $[13,14]$. Additionally, the stabilizer reduction during the synthesis of AgNPs normally leads to great toxicity of nanoparticles. Stabilizers such as polyvinyl pyrrolidone (PVP) and polyvinyl alcohol (PVA) were used to avoid the accumulation of the nanoparticles and therefore reduce the propensity to form large size particles. The stabilizer also provides an extra impact to the outer component of the nanoparticles with the oxide coating on the surface. This has a great attraction to acting together with the cells and hence producing cells damaged $[15,16]$.

\section{Fungi in AgNPs preparation}

Various fungi species containing ascomycete and basidiomycete were used to synthesize AgNPs, such as the intracellular and extracellular formation of fungi [17]. In fungi, the aqueous source of the fruiting form, mycelium, broth of mycelium, and fungi, is mainly used in the AgNPs synthesis procedure [18,19]. Furthermore, the fungus extract has irritating nutritive biomolecule complexes; for example, the polysaccharide is comprising of $\alpha$ and $\beta$ glucan, peptide (e.g., pleurostrin), hypsin, flavonoid, and lentin [20, 21]. In addition, ascorbic acid can perform as a normal preservative and a reducing agent to nanoparticles. Preparing AgNPs in this way was selected because of its great nutritional gratify, ecologically friendly procedure, little harvesting retro, non- pathogenicity, and non-toxicity. The formed product was prepared safely and cheaply due to the used, reducing agent. Ultimately, the fungus cultivation can be performed to produce healthy fungi, short reaping period, and free insecticide $[22,23]$.

\section{Applications of Fungal-synthesis nanoparticles}

Nanoparticles synthesized from fungal have significant biocatalytic properties [24, 25]. Figure 1 shows the catalytic influence of biosynthesized nanoparticles formed from fungus, which can be selected by enzyme immobilization. Below are example studies of AgNPs applications:

- The function of fungi as anti-mosquito studies. According to Banu and Balasubramanian [26], the synthesized nanoparticles from pathogenic fungi are active against the dengue vector. In another study by Soni and Prakash, the effect of AgNPs produced from fungi, such as $(F$. oxysporum), against vector insects was recorded [27].

- Sundaramoorthi et al., 2009 [28] have discovered the wound healing ability of nanoparticles formed from fungi in a typical rat trial. It was suggested that AgNPs enhances the wound healing by measuring the ratio of helical reduction and retro of epithelialization in dosage and time.

- Though AgNPs are synthesized by Lecanicillium lecanii, using cotton fabrics has displayed an inhibition activity against $S$. aureus and E. coli [29]. Textile cotton fabric can be used to avoid bacterial infections in hospitals. This is in consistent with Duran et al. [30] findings, where it was confirmed that the use of nanoparticles synthesized from the fungus $F$. 
oxysporum and combined into textile cotton fabrics yielded antibacterial activity against $S$. aureus [31].

- Fayaz et al. in 2009 [32] confirmed that the nanoparticles synthesized from T. viride and combined into a tinny film of sodium alginate increased antibacterial activity of the carrot. Compared to the control sample, an enhancement in their life was observed.

- Different PCR analyses have been prepared by Bharde et al. [33] for the fast detection of pathogenic fungus from little DNA concentrated. This bio-link nano PCR analysis has exposed high specificity and sensitivity compared to the conventional technique.

- The strain of multi-resistant bacteria has grown at a remarkable ratio and represents the main threat to new medicine [34]. The appearance of antibiotic resistance is the importance of multiple interactions of factors, which include the evolution and range of resistance mechanisms $[35,36]$. The increase in antibiotic resistance is produced by the common wrong usage habits of antibiotics for humans and animals. Throughout the past decade, knowledge about nano-medicine has been increased due to the high efficiency of many nano-associates against pathogenic microorganisms. The progression of non-toxic approaches for synthesizing nanoparticles will be the main step in nanotechnology to document their application in nanomedicine $[37,38]$.

- Determination of AgNPs with an antifungal agent, like fluconazole, mixture outcome was studied against a number of pathogenic fungi $[39,40]$. The fungi enabled the synthesis of AgNPs and showed antifungal action [41].

- There are a number of reports that showed the influence of fungal AgNPs on various viruses [42,43]. The findings showed that the nanoparticles reduced the structure of HIV that penetrates the human cells.

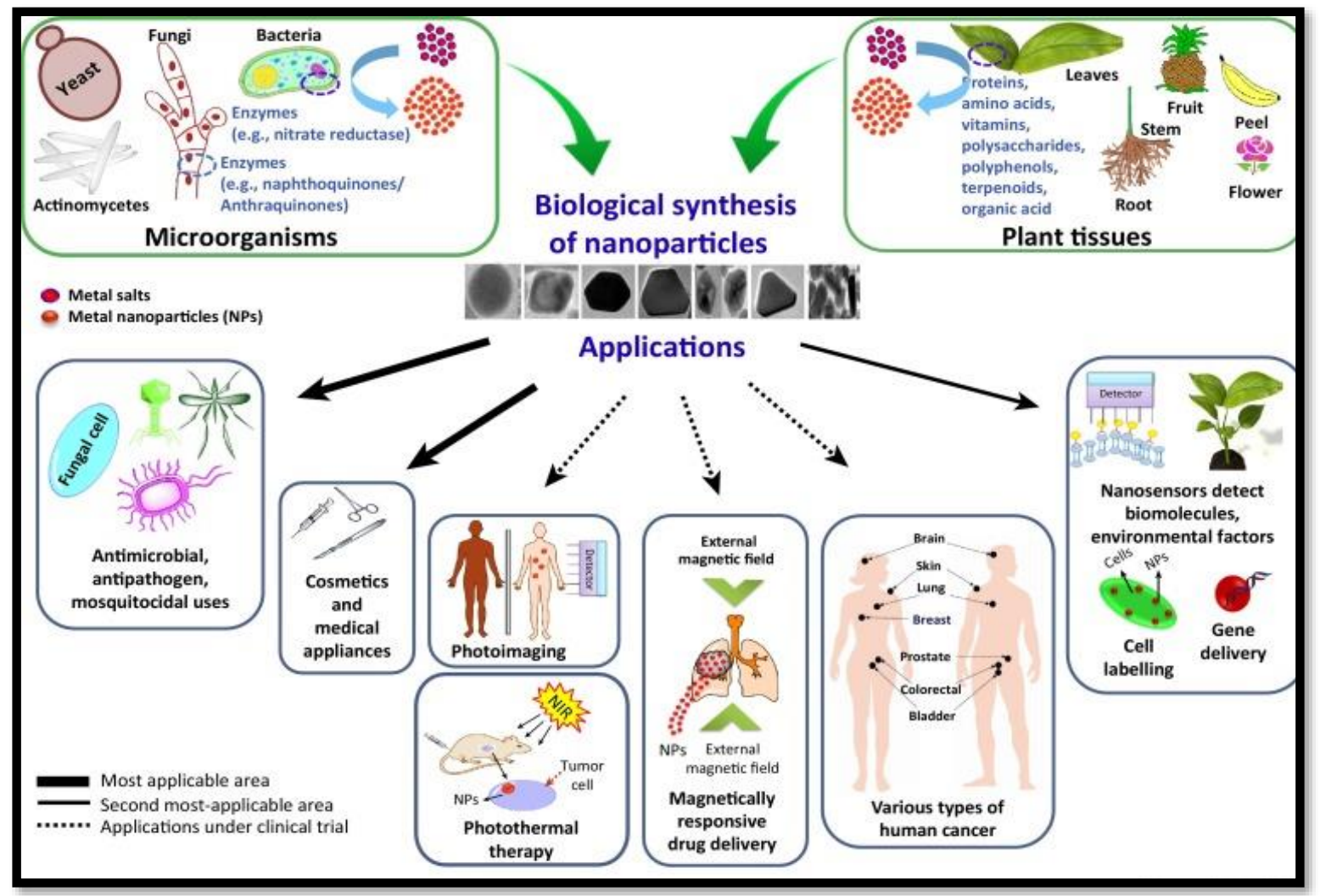

Figure 1. Scheme of biological synthesis of nanoparticles. 


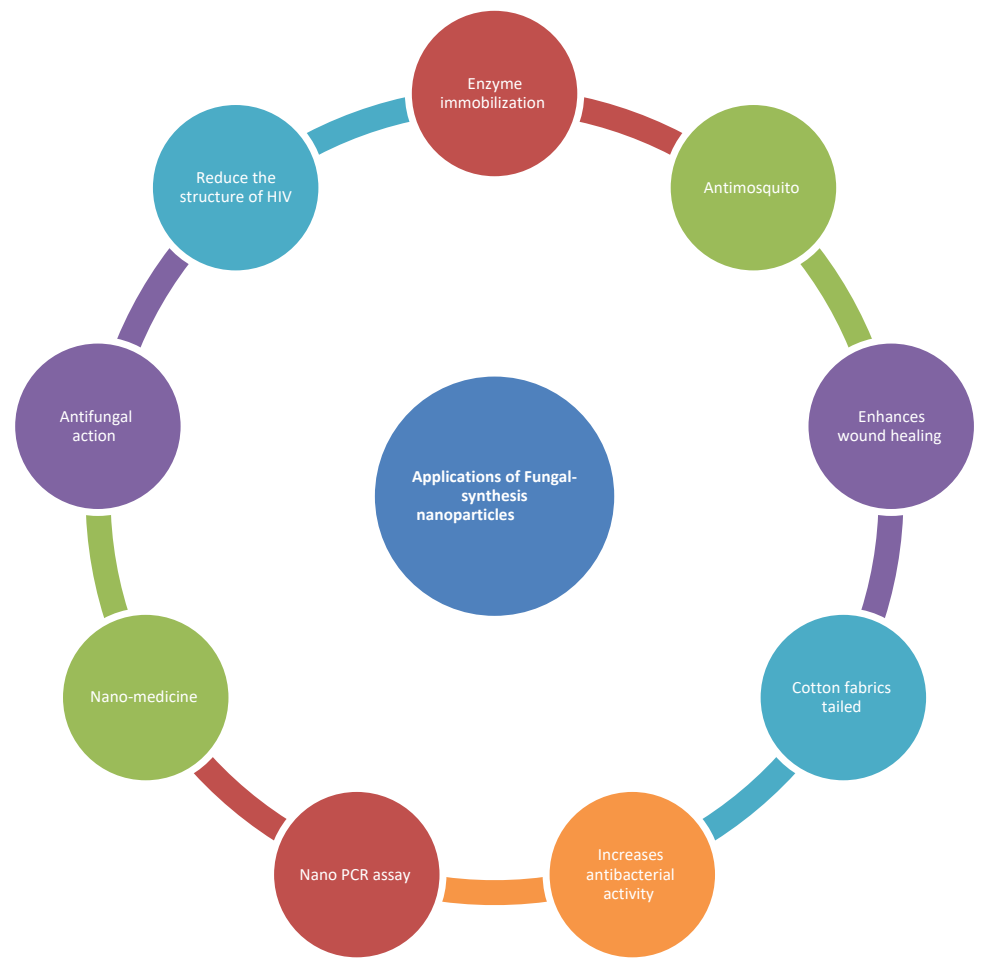

Figure 2. Applications of Fungal-synthesis nanoparticles.

\section{Conclusions}

Biosynthesis of nanoparticles is a fast and substitutional biochemical syntheses technique that has remarkable importance because of its friendliness to environmental, feasibility, and a wide range for applications. It is considered economical in different applications, particularly as antifungal, antiviruses, and antibacterial activity. $\mathrm{AgNO}_{3}$ was used as a raw material to prepared silver nanoparticles, which was successfully synthesized through the fungus and showed antifungal activity. The NPs used in treatment applications on fungal, bacterial, and viral infections to humans was found effective and promising.

\section{Funding}

This research received no external funding.

\section{Acknowledgments}

The authors like to thank the Department of Molecular and Medical Biotechnology at the College of Biotechnology/Al-Nahrain University and the Department of Chemistry at the College of Science/Al-Nahrain University for partially supporting this work.

\section{Conflicts of Interest}

The authors declare no conflict of interest.

\section{References}

1. Horky, P.; Skalickova, S.; Baholet, D.; Skladanka, J. Nanoparticles as a Solution for Eliminating the Risk of Mycotoxins. Nanomaterials (Basel) 2018, 8, https://doi.org/10.3390/nano8090727.

2. El-Adly, A.; Shabana, I. Antimicrobial Activity of Green Silver Nanoparticles against Fluconazole-resistant Candida albicans in Animal Model. Egyptian Journal of Botany 2018, 58, 119-132, https://doi.org/10.21608/ejbo.2018.1292.1110. 
3. Advances in Nanoengineering: Electronics, Materials and Assembly. Published by imperial college press and distributed by world scientific publishing co.: Volume 3, 2007; pp. 328.

4. Lai, M.Y.; Hsu, J.F.; Chu, S.M.; Wu, I.H.; Huang, H.R.; Chiang, M.C.; Fu, R.H.; Tsai, M.H. Risk Factors and Outcomes of Recurrent Candidemia in Children: Relapse or Re-Infection? Journal of clinical medicine 2019, 8, https://doi.org/10.3390/jcm8010099.

5. Bhangale, H.G.; Bachhav, S.; Nerkar, D.; Sarode, K.M.; Patil, D. Study on Optical Properties of Green Synthesized Silver Nanoparticles for Surface Plasmon Resonance. Journal of Nanoscience and Technology 2019, 5, 658-661, https://doi.org/10.30799/jnst.230.19050203.

6. Mulani, M.S.; Kamble, E.E.; Kumkar, S.N.; Tawre, M.S.; Pardesi, K.R. Emerging Strategies to Combat ESKAPE Pathogens in the Era of Antimicrobial Resistance: A Review. Frontiers in microbiology 2019, 10, 539-539, https://doi.org/10.3389/fmicb.2019.00539.

7. Karagkiozaki, V.; Logothetidis, S.; Kalfagiannis, N.; Lousinian, S.; Giannoglou, G. Atomic force microscopy probing platelet activation behavior on titanium nitride nanocoatings for biomedical applications. Nanomedicine: Nanotechnology, Biology and Medicine 2009, 5, 64-72, https://doi.org/10.1016/j.nano.2008.07.005.

8. Groneberg, D.A.; Giersig, M.; Welte, T.; Pison, U. Nanoparticle-based diagnosis and therapy. Curr Drug Targets 2006, 7, 643-648, https://doi.org/10.2174/138945006777435245.

9. Yahyaei, B.; Pourali, P. One step conjugation of some chemotherapeutic drugs to the biologically produced gold nanoparticles and assessment of their anticancer effects. Scientific Reports 2019, 9, https://doi.org/10.1038/s41598-019-46602-0.

10. Huang, W.; Yan, M.; Duan, H.; Bi, Y.; Cheng, X.; Yu, H. Synergistic Antifungal Activity of Green Synthesized Silver Nanoparticles and Epoxiconazole against Setosphaeria turcica. Journal of Nanomaterials 2020, 2020, https://doi.org/10.1155/2020/9535432.

11. Matei, A.; Matei, S.; Matei, G.; Cogalniceanu, G.; Cornea, C.P. Biosynthesis of silver nanoparticles mediated by culture filtrate of lactic acid bacteria, characterization and antifungal activity. The EuroBiotech Journal 2020, 4, 97-103, https://doi.org/10.2478/ebtj-2020-0011.

12. White, R.J.; Budarin, V.L.; Moir, J.W.B.; Clark, J.H. A sweet killer: mesoporous polysaccharide confined silver nanoparticles for antibacterial applications. International journal of molecular sciences 2011, 12, 5782-5796, https://doi.org/10.3390/ijms12095782.

13. Ahmed, D.S.; Mohammed, T.H.; Risan, M.H.; Najim, L.H.; Mohammed, S.A.; Yusop, R.M.; Yousif, E. Green synthesis of silver nanoparticles by plants extract. International Journal of Chemical and Process Engineering Research 2019, 6, 1-6.

14. Sastry, M.K.S.; Mayya, K.S.; Bandyopadhyay, K. PH Dependent changes in the optical properties of carboxylic acid derivatized silver colloidal particles. Colloids and Surfaces A: Physicochemical and Engineering Aspects 1997, 127, 221-228.

15. Jalal, M.; Ansari, M.A.; Alzohairy, M.A.; Ali, S.G.; Khan, H.M.; Almatroudi, A.; Siddiqui, M.I. Anticandidal activity of biosynthesized silver nanoparticles: effect on growth, cell morphology, and key virulence attributes of Candida species. Int $J$ Nanomedicine 2019, 14, 4667-4679, https://doi.org/10.2147/ijn.S210449.

16. Verma, V.C.; Kharwar, R.N.; Gange, A.C. Biosynthesis of antimicrobial silver nanoparticles by the endophytic fungus Aspergillus clavatus. Nanomedicine (London, England) 2010, 5, 33-40, https://doi.org/10.2217/nnm.09.77.

17. Gurunathan, S. Rapid biological synthesis of silver nanoparticles and their enhanced antibacterial effects against Escherichia fergusonii and Streptococcus mutans. Arabian Journal of Chemistry 2019, 12, 168-180, https://doi.org/10.1016/j.arabjc.2014.11.014

18. Liu, M.; Zhou, Q.; Wang, J.; Liu, J.; Qi, C.; Lai, Y.; Zhu, H.; Xue, Y.; Hu, Z.; Zhang, Y. Anti-inflammatory butenolide derivatives from the coral-derived fungus Aspergillus terreus and structure revisions of aspernolides D and G, butyrolactone VI and 4', $8^{\prime \prime}$-diacetoxy butyrolactone VI. RSC Advances 2018, 8, 13040-13047, https://doi.org/10.1039/C8RA01840E.

19. Zomorodian, K.; Pourshahid, S.; Sadatsharifi, A.; Mehryar, P.; Pakshir, K.; Rahimi, M.J.; Arabi Monfared, A. Biosynthesis and Characterization of Silver Nanoparticles by Aspergillus Species. BioMed Research International 2016, 2016, https://doi.org/10.1155/2016/5435397.

20. Adeeyo, A.O.; Odiyo, J.O. Biogenic synthesis of silver nanoparticle from mushroom exopolysaccharides and its potentials in water purification. Open Chem. 2018, 5, 64-75, https://doi.org/10.2174/1874842201805010064.

21. Vanaja, M.; Annadurai, G. Coleus aromaticus leaf extract mediated synthesis of silver nanoparticles and its bactericidal activity. Applied Nanoscience 2013, 3, 217-223, https://doi.org/10.1007/s13204-012-0121-9.

22. Shah, S.; Gaikwad, S.; Nagar, S.; Kulshrestha, S.; Vaidya, V.; Nawani, N.; Pawar, S. Biofilm inhibition and anti-quorum sensing activity of phytosynthesized silver nanoparticles against the nosocomial pathogen Pseudomonas aeruginosa. Biofouling 2019, 35, 34-49, https://doi.org/10.1080/08927014.2018.1563686.

23. Roco, M.C. International Perspective on Government Nanotechnology Funding in 2005. Journal of Nanoparticle Research 2005, 7, 707-712, https://doi.org/10.1007/s11051-005-3141-5. 
24. Marooufpour, N.; Alizadeh, M.; Hatami, M.; Lajayer, B.A. Chapter 3. Biosynthesis of nanoparticles by different groups of bacteria. In: Microbial Nanobionics Nanotechnology in the Life Sciences. Prasad, R. (ed.). Springer Nature Switzerland AG: 2019; 63-85.

25. Mishra, A.; Kumari, M.; Pandey, S.; Chaudhry, V.; Gupta, K.C.; Nautiyal, C.S. Biocatalytic and antimicrobial activities of gold nanoparticles synthesized by Trichoderma sp. Bioresource Technology 2014, 166, 235-242, https://doi.org/10.1016/j.biortech.2014.04.085.

26. Al-Saffar, A.; Yousif, E.; Alshanon, A. Gold Nanoparticles Detection by Plants Extracts - A Review. Science Letters 2018, 12, 41-58.

27. Banu, A.N.; Balasubramanian, C. Myco-synthesis of silver nanoparticles using Beauveria bassiana against dengue vector, Aedes aegypti (Diptera: Culicidae). Parasitology Research 2014, 113, 2869-2877, https://doi.org/10.1007/s00436-014-3948-z.

28. Soni, N.; Prakash, S. Fungal-mediated nano silver: an effective adulticide against mosquito. Parasitology Research 2012, 111, 2091-2098, https://doi.org/10.1007/s00436-012-3056-X.

29. Sundaramoorthi, C.; Mathews, D.; Sivanandy, D.P.; Kalaiselvan, V.; Rajasekaran, A. Biosynthesis of silver nanoparticles from Aspergillus niger and evaluation of its wound healing activity in experimental rat model. International Journal of PharmTech Research 2009, 1, 1523-1529.

30. Namasivayam, S.K.R. Silver nanoparticle synthesis from lecanicillium lecanii and evolutionary treatment on cotton fabrics by measuring their improved antibacterial activity with antibiotics against Staphylococcus aureus (ATCC 29213) and E coli (ATCC 25922) strains. International Journal of Pharmacy and Pharmaceutical Sciences 2011, 3, 190-195.

31. Duran, N.; Marcato, P.; Souza, G.; Alves, O.; Esposito, E. Antibacterial Effect of Silver Nanoparticles Produced by Fungal Process on Textile Fabrics and Their Effluent Treatment. Journal of Biomedical Nanotechnology 2007, 3, 203-208, https://doi.org/10.1166/jbn.2007.022.

32. Hasson, S.; Al-Awady, M.; Aubaid, A.; Al-Azawi, I.; Ali, A. Boosting Antimicrobial Activity of Imipenem in Combination with Silver Nanoparticles towards S. fonticola and Pantoea sp. Nano Biomedicine and Engineering 2019, 11, 200-214, https://doi.org/10.5101/nbe.v11i2.p200-214.

33. Mohammed Fayaz, A.; Balaji, K.; Girilal, M.; Kalaichelvan, P.T.; Venkatesan, R. Mycobased Synthesis of Silver Nanoparticles and Their Incorporation into Sodium Alginate Films for Vegetable and Fruit Preservation. J Agric Food Chem 2009, 57, 6246-6252, https://doi.org/10.1021/jf900337h.

34. Bharde, A.; Rautaray, D.; Bansal, V.; Ahmad, A.; Sarkar, I.; Yusuf, S.M.; Sanyal, M.; Sastry, M. Extracellular biosynthesis of magnetite using fungi. Small 2006, 2, 135-141, https://doi.org/10.1002/smll.200500180.

35. Lavigne, L.M.; Schopf, L.R.; Chung, C.L.; Maylor, R.; Sypek, J.P. The role of recombinant murine IL-12 and IFN-gamma in the pathogenesis of a murine systemic Candida albicans infection. J Immunol 1998, 160, 284-292.

36. Sun, J.; Deng, Z.; Yan, A. Bacterial multidrug efflux pumps: Mechanisms, physiology and pharmacological exploitations. Biochemical and Biophysical Research Communications 2014, 453, 254-267, https://doi.org/10.1016/j.bbrc.2014.05.090.

37. Loo, Y.Y.; Rukayadi, Y.; Nor-Khaizura, M.A.; Kuan, C.H.; Chieng, B.W.; Nishibuchi, M.; Radu, S. In Vitro Antimicrobial Activity of Green Synthesized Silver Nanoparticles Against Selected Gram-negative Foodborne Pathogens. Front Microbiol 2018, 9, https://doi.org/10.3389/fmicb.2018.01555.

38. Allahverdiyev, A.M.; Kon, K.V.; Abamor, E.S.; Bagirova, M.; Rafailovich, M. Coping with antibiotic resistance: combining nanoparticles with antibiotics and other antimicrobial agents. Expert review of antiinfective therapy 2011, 9, 1035-1052, https://doi.org/10.1586/eri.11.121.

39. Khandel, P.; Shahi, S.K. Mycogenic nanoparticles and their bio-prospective applications: current status and future challenges. Journal of Nanostructure in Chemistry 2018, 8, 369-391, https://doi.org/10.1007/s40097-018-0285-2.

40. Gajbhiye, M.; Kesharwani, J.; Ingle, A.; Gade, A.; Rai, M. Fungus-mediated synthesis of silver nanoparticles and their activity against pathogenic fungi in combination with fluconazole. Nanomedicine 2009, 5, 382-386, https://doi.org/10.1016/j.nano.2009.06.005.

41. Elamawi, R.M.; Al-Harbi, R.E.; Hendi, A.A. Biosynthesis and characterization of silver nanoparticles using Trichoderma longibrachiatum and their effect on phytopathogenic fungi. Egyptian Journal of Biological Pest Control 2018, 28, https://doi.org/10.1186/s41938-018-0028-1.

42. Ray, S.; Sarkar, S.; Kundu, S. Extracellular biosynthesis of silver nanoparticles using the mycorrhizal mushroom Tricholoma crassum (Berk.) SACC: Its antimicrobial activity against pathogenic bacteria and fungus, including multidrug resistant plant and human bacteria. Digest Journal of Nanomaterials and Biostructures 2011, 6, 1289-1299.

43. Elechiguerra, J.L.; Burt, J.L.; Morones, J.R.; Camacho-Bragado, A.; Gao, X.; Lara, H.H.; Yacaman, M.J. Interaction of silver nanoparticles with HIV-1. J Nanobiotechnology 2005, 3, https://doi.org/10.1186/14773155-3-6.

44. Qidwai, A.; Pandey, A.; Kumar, R.; Shukla, S.K.; Dikshit, A. Advances in biogenic nanoparticles and the mechanisms of antimicrobial effects. Indian J. Pharm. Sci. 2018, 80, 592-603. 